\title{
Using a Partnership in Industry to Link Theory and Practice in Undergraduate Courses
}

\author{
Elsje Scott and Maureen Tanner \\ University of Cape Town, Cape Town, South Africa \\ elsje.scott@uct.ac.za, mc.tanner@uct.ac.za
}

\begin{abstract}
The Information Systems (IS) profession is known as one of the most dynamic fields in our current day and age. Rapid advances in Information and Communication Technologies (ICTs) increase the dependence of organizations on these ICTs and create a greater need for IS competence. This demand constitutes serious challenges to academia to provide graduates with the necessary skill set to fulfil their roles in industry and to cope more effectively with real life problems. In an attempt to address this skills gap, a theory of coherent practice was developed to act as a framework for creating a synthesis of theory and practice when designing curricula for undergraduate courses. This paper reports on a specific implementation that led to an industry partnership, and the construction of a Case study to support a flipped classroom approach and provide context for a real life problem. In addition, it guided the design of a set of carefully structured interventions directing student evolution through different stages of development. Although further refinement to the implementation of the theory in the design of second year courses is needed, the value of the approach in preparing students more effectively for professional practice is already apparent in student feedback and in their performance in the courses.
\end{abstract}

Keywords: flipped classroom approach, coherent practice, deep approaches to learning, integrated and interactive environment, three stages of behavior.

\section{Introduction}

The alignment of graduate attributes to that of industry's needs has been a contentious issue for the past decade or more. Information and Communication Technologies (ICTs) have become ubiquitous in the workplace and technologies are fast changing. As a result, the attributes and capabilities that should be developed to prepare Information Systems (IS) graduates to cope with the challenges of the real world are constantly under review in the literature (Hirschheim \& Klein, 2012; McMurtrey, Downey, Zeltmann, \& Friedman, 2008; Beard, Schwieger, \& Surendran, 2007; Seymour, Scott, Meyerowitz, Malamoglou, \& Morar, 2006; Gallivan, TruexIII, \& Kvasny, 2004).

Material published as part of this publication, either on-line or in print, is copyrighted by the Informing Science Institute. Permission to make digital or paper copy of part or all of these works for personal or classroom use is granted without fee provided that the copies are not made or distributed for profit or commercial advantage AND that copies 1) bear this notice in full and 2) give the full citation on the first page. It is permissible to abstract these works so long as credit is given. To copy in all other cases or to republish or to post on a server or to redistribute to lists requires specific permission and payment of a fee. Contact Publisher@InformingScience.org to request redistribution permission.
For example, Gupta and Wachter (1998, p. 427) argue that "few occupations have grown so rapidly as the information systems profession", and state that this phenomenal rate of change constantly contributes to the "gap between what industry wants characteristically in IS personnel and what academia provides them" (p.428). More than a decade later this is still the sentiment of many. Richards, Marrone and Vat- 
anasakdakul (2011, p. 1) concur that it is important to find a balance with what is foundational and core, and then to determine how to adapt and design "course content and delivery to meet the current and future needs for knowledge and skills in industry".

The dilemma is thus not only to identify what needs to be done, but also how it should be done (Beard et al., 2007). There is limited research into how students should overcome this gap. This paper reports on an implementation of two undergraduate (second year) courses where both the "what" and the "how" were addressed. The same cohort of students normally attends both these courses as they run sequentially, with the first one being a prerequisite of the next. It, therefore, makes sense to use a special case study as the central theme to link these courses. Flyvberg (2006) argues that a case study provides valuable concrete and context-dependent knowledge which is at the core of research on learning. The special case study for the courses was developed in a joint venture by faculty and an industry partner who wanted to become involved in the design of the various deliverables of the courses. The rationale is that if a case study is locally developed, student can identify with it much easier. One of the objectives of this partnership agreement was to contribute to these courses in such a way that students become aware of the role that context plays in finding a solution to business problems. When business systems are developed they are socially constructed and social constructions are influenced by culture (Tedre, Sutinen, Käkhönen, \& Kommers, 2003). The same authors argue that "we should give culturally bound knowledge the chance to support the students' mental imagery" (2003, p. 176).

In addition, it is necessary that students gain experience of the messy and ill-defined problems that are created by continuously changing workplace demands (Kroeze et al., 2011; Cicmil, 2006; Checkland, 1972). Joint ventures, between academia and industry, are critical in facilitating some form of cohesion between theory and practice (Land et al., 2009). Raelin (2007, p. 495) argues that if students partake in structuring and evaluating their own learning, they will be better equipped in linking theory and practice to become "thoughtful practitioners".

The intention of this paper is, first, to discuss different approaches to learning that can be used to prepare students for professional practice. The value of using a case study to integrate the different sections of the courses and to provide students with the ability to conceptualize a problem within a particular context cannot be underestimated. Secondly, the pedagogy comprising a theoretical framework that underpins the design of the curricula is briefly discussed. Finally, the paper reports on an action experiment of implementing the principles of this theory of coherent practice to structure the different interventions or deliverables for the courses and to execute the two courses.

\section{Creating a Learning Environment}

Ramsden (2003, p. 8) argues that "teaching and learning in higher education are inextricably and elaborately linked". In recent years, there has been a shift to an environment that supports a student-centered approach that provides students with a perception that they can take control over their learning as well as to co-create the learning environment. This not only fosters self-directed, flexible and experiential learning (O’Neill \& McMahon, 2005), but it also encourages students to become more engaged in the learning activities. Since "learning is a gradual process of shaping understanding", it is most likely that a deep approach to studying will not only be transformative, but will also result in higher levels of understanding (Entwistle \& Peterson, 2004, p. 410; Entwistle, 2000).

A deep approach to learning does not focus on student factors alone, but ensures that both the teacher and students are fully engaged in the learning process (Biggs \& Tang, 2011). It is particularly sensitive to the context in which the learning is taking place. A deep approach to learning also nurtures a keen interest in learning activities, making learning fun and encouraging a 
"need-to-know" attitude. Webb (1997) contends that surface learning is not "all that bad", as it can be related to the hermeneutic principle that underpins a constant and recursive search for understanding by working back and forth from surface to deep understanding.

Activities like these form an integral part of all learning experiences and sense making activities. Different strategies like experiential learning, action learning and project-based learning can all be implemented to encourage effective learning. These strategies influence the way in which students take ownership for their learning and how they are prepared for professional practice.

Kolb's (1984) experiential learning model comprises a cycle of four steps commencing with a concrete experience, followed by observations and reflections, the formation of abstract concepts and then the testing of the implications of concepts in new situations. Action learning is sometimes confused with experiential learning. While these strategies do share philosophical assumptions, action learning can be distinguished as a flexible approach with "many faces" (Marsick \& O'Niel, 1999) that has at its core "action-oriented learning in organizations, learning to solve real, not simulated problems, and cooperative learning with work and business partners in the concrete work context/environment" (Zuber-Skerritt, 2002).

From the above, it is evident that a strategy to incorporate of real world projects in a curriculum guides students to develop a mix of technical and managerial skills that will better equip them to face the challenges of the business environment (Mendoza \& Ellis, 2003). This is in line with Gerogiannis and Fitsilis' (2006) argument that a project-based approach emphasizes collaboration and effective communication skills. The customized case study developed by industry for the second year students therefore provides ideal opportunities for students to become actively engaged, while they also master the art of inquiry and of linking theory to its practical application. Although the project for the second course will still be of a limited scope, students already develop core competencies at an individual level at an early stage in their degree.

\section{The Theory of Coherent Practice}

As mentioned at the beginning of this paper, institutions of tertiary education face the challenge of producing graduates who are sufficiently prepared for professional practice when they commence their careers. There is consensus in the literature that producing well-rounded IS/IT graduates in a world of complex requirements places stringent demands on IS educators. It is incumbent on educators to continuously revise and change programs and curricula so as to better equip students for the marketplace.

Since the main aim of education is to facilitate a change in learners' knowledge, educators should also convey a critical awareness of the different conceptualizations of the discipline to their learners. This may help students to understand their role as potential IS practitioners. It is also important to create spaces and opportunities for students to become co-constructors of this body of knowledge. For these reasons, it is evident that the development of a comprehensive and coherent pedagogy needed careful consideration.

In the first place, this pedagogy was developed to address the limitations experienced in the IS curricula over the past years. Its focus is to create a learning environment that will stimulate a new mindset amongst students to be conscious of the complex reality of projects, as well as the related social processes and their emotional aspects. IS2010 is the latest major revision of curriculum guidelines for undergraduate degree programs in Information Systems (Topi et al., 2010). Other major updates, prior to this one, were the IS 2002 and IS'97 versions (Gorgone et al., 2002). Although IS2010 recognizes information systems as complex systems within a challenging environment that need specialized and unique resources and expertise, the development stream was listed as a non-core knowledge area for the undergraduate curriculum. Notwithstanding the fact that these topics are notoriously difficult to teach and students find it hard to learn to 
program and to develop software applications (Rogerson \& Scott, 2010; Jenkins, 2002) a basic knowledge of the development environment remains "crucial for understanding and appreciating analysis, modeling and managerial outcomes" (Sewchurran in Kroeze et al., 2011).

Secondly this pedagogy uses theory to understand the learning process that takes place within a student, which itself is a theory building process. The way in which students internalize knowledge is thus inextricably intertwined with the notion of using theory to explain the pedagogy of a course that will link and integrate two different courses in a student-centered and student-directed way (Scott, 2012; Moore, 2006). Although this paper focusses on an implementation of a second year course, and the theory was initially developed for capstone or exit level courses, most of the principles for designing a capstone course remain valid when designing other undergraduate courses as will become apparent in the subsequent sections.

If a learning environment is interactive and integrated, it has the potential to provide a unique opportunity to "enact" meaning-making activities towards constructing and internalizing knowledge. It is in such a process that students can be groomed to practice innovative ways that will enhance their capabilities and better prepare them to face challenges in industry. In the third place the pedagogy therefore facilitates the design of the interventions that is incorporated into the curriculum of a course in such a way that it will foster deep approaches to learning. Figure 1 provides an illustration of the conceptual framework for the theory of coherent practice that underpins this pedagogy, whereas Figure 2 depicts the pedagogy.

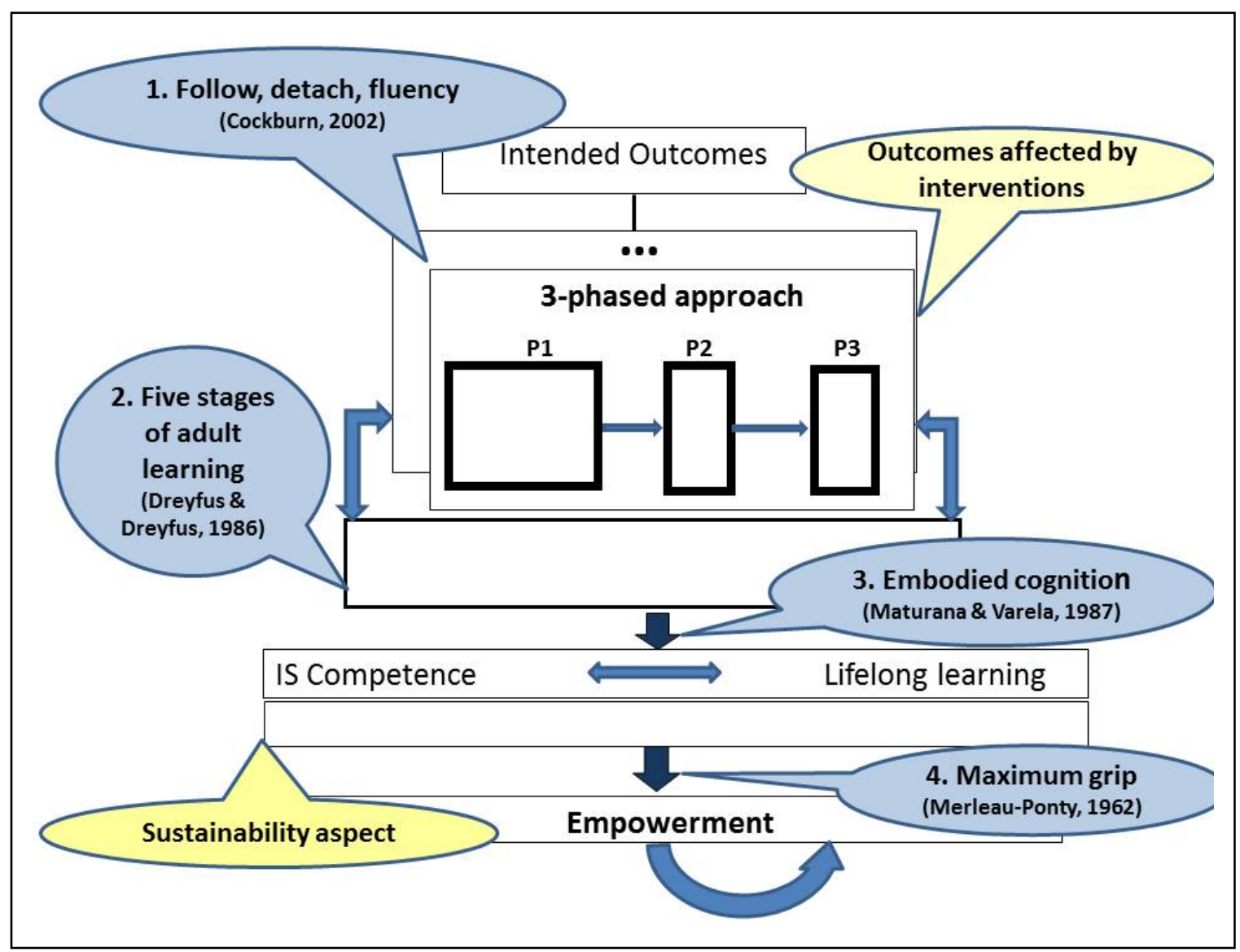

Figure 1: The Conceptual Framework of the Theory of Coherent Practice (Scott, 2012)

As seen in the literature, interventions like projects and teamwork help to constitute an integrated environment which in turn fuses practical experiences with theoretical concepts to grow compe- 
tence. An interactive environment, on the other hand, positively influences students to focus on doing, explaining, understanding and believing.

In this pedagogy (see Figure 2), the conceptual framework in Figure 1, acts as a bridge between the paradigms which explains the theoretical issues and the practice of investigating and addressing those issues. A natural entry point for the conceptual framework is the determination of the intended graduate outcomes. The intended outcomes of selected or constructed interventions (activities and deliverables) that form part of a course should be to: nurture learning and higher order learning; develop a diverse set of skills; provide students with rich real-life experience, and encourage changes in student attributes and behavior. These outcomes can be built on until a student graduates and embarks on a career.

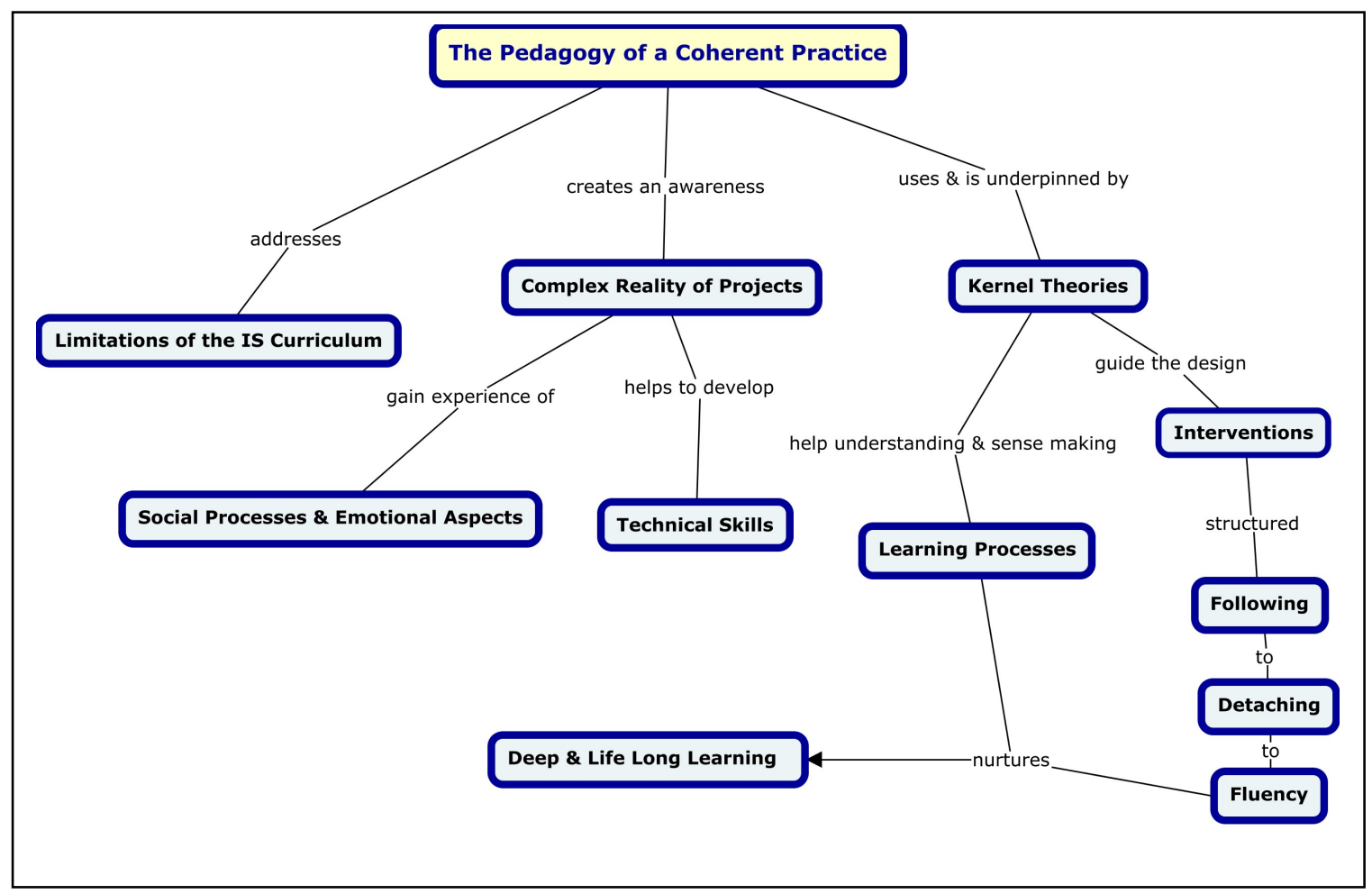

Figure 2: The Pedagogy of a Coherent Practice

Several theories act as kernel theories for the theory of coherent practice. The first of which is Cockburn's (2002) theory of three stages of behavior (different levels of listening) of follow, detach and fluency. This theory guides the design and the structuring of interventions to ensure that they are carefully aligned and linked. Students first encounter Phase 1 (P1) -follow interventions that are controlled and provide step-by-step guidance. This typically happens in the coding workshops where students are carefully guided to understand good programming principles and design. Phase 2 (P2) interventions are conducted in a secure environment, but provide students with less assistance to encourage detaching. These types of deliverables could refer to the preparing of documentation for their projects using templates or in completing tasks in tutorials and theory workshops. Phase 3 (P3) interventions require students to become fluent and act autonomously (to some extent), such as when they develop their software development team project.

The second theory refers to the five stages of skills acquisition (Dreyfus \& Dreyfus, 1986). Dreyfus and Dreyfus (1986) define the five stages of skills development as: novice, advance beginner, competence, proficiency and expertise. This theory assists in a sense-making process to deter- 
mine what level of competency students have reached and what is needed to allow them to transcend to the next level through enhanced skills, experience, deep approaches to learning and changes in attitude. It is a dynamic and ongoing process of fusing the practical experience of projects with theoretical concepts and phenomena. In simple terms, this involves learning by doing to achieve embodied cognition constituting the third theory (Maturana \& Varela, 1987).

This continuous process of skillful activity that brings a person closer to an optimum level can also be defined by the concept of maximal grip (Merleau-Ponty, 1962), the fourth theory. Merleau-Ponty (1962) argues that human beings always tend to improve their current situation to achieve maximum grip. It is only because what he calls the intentional arc is steadily improved, refined and enriched that the body moves into a state of unconscious competency towards maximum grip.

Evidence exist that these internalized competencies enhanced by elements of lifelong learning comprising explicit and tacit knowledge, as well as attitudes like motivation and ownership, will finally lead to passionate and committed IS graduates empowered to cope with the real-life issues they will have to face. The refinement of this conceptual framework led to the definition of a theory for coherent practice "that prescribes how a set of carefully designed interventions can be constructed and implemented to" development competence in IS graduates or students in other exit level courses that will equip them to sustain this competence by lifelong learning (Scott, 2012 , p. 223). This theory is structured to exhibit the anatomy of a design theory comprising eight components as specified by Gregor and Jones (2007). These include the purpose and scope of the theory; its constructs; principles of form and function; artifact mutability; testable propositions; justificatory knowledge (kernel theories) as listed above; principles of implementation; and an expository instantiation referring to the course being designed in this case (Scott, 2012, pp. 223-224).

The theory is based on various "principles of implementation" that provide opportunities to prescribe the actions in the design of the curricula for both the Systems Analysis (INF2009F) and Systems Design and Implementation (INF2011S) courses. These principles are formulated to incorporate a prescribed action and the goal to be accomplished when the action is completed (Kuechler \& Vaishnavi, 2008). They assist in developing mechanisms for understanding, explaining and prescribing relevant actions, but then also require support for alternative approaches. Several principles were implemented to guide the design of the instances of the two undergraduate courses.

- a focus on project phenomena, which assists to highlight and address the complexities inherent in human interaction. Real life project experiences with unexpected incidences and ambiguities built into the case study challenge students to make difficult decisions or assumptions.

- a framework for coding practices (controlled quality) that provide a sound foundation for progressing towards crafted quality. A series of practical coding workshops provide scaffolding and guide students to develop a pilot system to serve as an exemplar for their team project.

- meaning making activities to make sense of experience for learning and developing perspectives. This will typically start in phase 2 (P2) interventions where students are challenged to reflect and apply critical reasoning.

- thinking and reasoning effectively about behavior to experience the value of practical knowledge (practicing double loop learning).

- a reflective practice that involves the body and the mind to achieve reflection for action, reflection in action and reflection on action that will create knowing in action. Various 
opportunities were created for reflection during the different stage of learning as discussed the latter sections of this paper. For exit level courses more prominence is given to this section.

- a synthesis of theory and practice to develop thoughtful practitioners. Understanding the customized case study developed by the industry partner as general theme in designing tutorials, class exercises and the project components as well as the industry involvement give students a real life experience and a feel for practice.

- transforming conceptual knowledge into contextual knowledge to nurture and achieve transcendence. The case study and central theme throughout the year provided ample opportunities for students to practice analysis skills and apply the theoretical knowledge gained in the course.

- avoiding a slavish adherence to method, while an agility to change should be encouraged to nurture innovative and creative solutions.

- experience in working in teams for personal growth.

\section{Methodology}

The paper employs a longitudinal design science research approach with the specific focus on designing courses in the undergraduate stream as a foundation to subsequent deliveries of capstone courses to potential graduates. The instances of the courses delivered constituted action experiments in this approach. A case study, specially designed by the industry partner, provided the context for this particular instantiation and was an ideal opportunities for innovation. Flyvbjerg (2006) argues that a case study approach provides the necessary case-based knowledge that is vital for students to advance from "rule-based" beginners to "virtuoso experts". He believes that well-chosen case studies help students to achieve competence, whereas contextindependent rules and facts will be counterproductive and pull a student back to a beginner's level. It was therefore important that a systematic approach should be followed to develop the curriculum in such a way that the interventions were carefully designed and linked to the case study.

\section{Aligning Undergraduate Courses}

A flipped classroom approach was followed for the Systems Analysis (INF2009F) and Systems Design and Implementation (INF2011S) courses (see Figure 3). A flipped classroom approach was adopted as it enables students to take control of their learning and co-create their learning environment while being more engaged. The design of the deliverables and interventions required for this approach was guided by the theory of coherent practice (Scott, 2012, p. 148).

The overall approach was designed to be interactive and integrated, which further "enacted" meaning-making activities enabling students to construct and internalize knowledge. The case study was used as a golden thread to link theory and practice in both the first semester and the second semester course and to guide the learning while preparing the students for challenges faced in industry. The case study developed for 2014 referred to a manufacturer and importer of confectionary and soft drinks in the Western Cape region, called Poppel. Poppel was said to have a large number of trade customers, café's, spazza shops, local bars and retail chains. The case study discussed the most important processes in the business chain, from manufacturing to inventory management and customer services and it also touched on some future directions. The scenarios described provided rich opportunities for designing several interventions. 


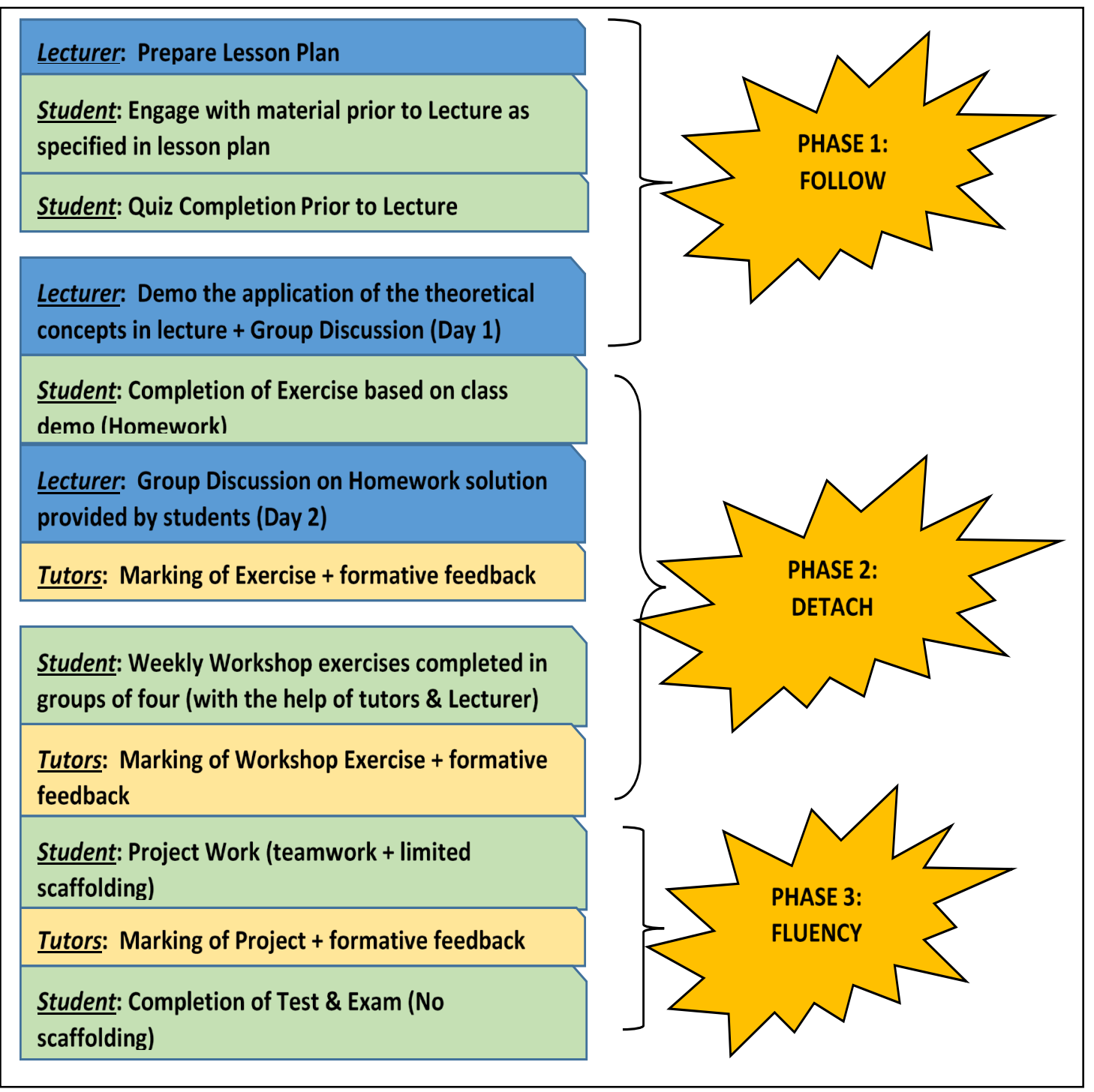

Figure 3: The Flipped Classroom Approach and Stages of Behavior

As will be described in the following sub-sections, the approach placed extensive emphasis on doing, explaining, understanding and believing through meaning-making activities. In addition, Cockburn's (2002) theory of the three stages of behavior (follow, detach and fluency) underpinned the design and the structure of the interventions and deliverables.

\section{Phase 1: Follow}

\section{Lesson plan \& quizzes}

During Phase 1, interventions were controlled and provided step-by-step guidance to the students. This phase was initiated by the conceptualization of a lesson plan for the students. The lesson plan acted as a road map which provided a detailed overview of the tasks to be completed by the students on a daily basis. It also detailed the deliverables (quiz, exercises and workshops) that they were expected to complete (with deadlines) prior to each lecture. This provided the necessary structure around the pre-class assignments. Such structure was required in order for the students to feel guided while they simultaneously took responsibility for their learning. 
Each lesson plan was composed of 3 parts: (1) a general overview of the topics to be covered in the following weeks, (2) a description of the learning objectives for each topic, and (3) a detailed description of the tasks to be completed by the students prior to a specific lecture. These tasks could include reading of slides, research articles and chapters in books, as well as watching Lynda.com and YouTube videos. The date by which the corresponding quiz was to be completed as well as whether an exercise would be associated with a particular topic were also specified.

Using the lesson plan as a road map, students were then required to engage with the course material in preparation for the exercises and group discussions. They were also required to complete quizzes within the deadlines specified in the lesson plan. Each quiz consisted of simple questions derived from the prescribed course material; students were required to complete $80 \%$ of all quizzes in order to be granted permission to participate in the final exam. The $80 \%$ quiz compulsory completion rate ensured that students engaged with the material and were ready for the lectures. However, the quizzes did not count for marks.

\section{Demo}

After having gone through the recommended material specified in the lesson plan and completed the quiz, it was anticipated that students would attend lectures with some basic understanding of the theoretical concepts. However, they would not have had the opportunity to apply these concepts yet.

The first lecture on a specific topic was thus typically dedicated to a demonstration of how to apply the specific theoretical concept to solve a business problem from a simple case study. Conducting the demo in front of the students was extremely valuable as it (1) enabled the lecturer to identify and address gaps in the students' understanding, and (2) enabled the students to ask rich questions while the demo was being conducted while simultaneously reflecting on their current level of understanding. Questions from the students were more targeted and reflective as they had engaged with the material beforehand, resulting in very interactive sessions.

\section{Phase 2: Detach}

\section{Exercises}

During Phase 2 (P2), interventions were conducted in a secure environment, but these provided students with less assistance in order to encourage detaching. Students were asked to complete an exercise as homework. The aim of these exercises was to allow them to think and reason effectively and to initiate detaching.

An exercise was typically based on a different and slightly more complex case study. It was valuable for the students to complete the exercise as homework as it challenged them into thinking more deeply about the concept being taught. It also gave them the opportunity to further reflect on what had been demonstrated to them in lecture and identify gaps in their understanding. They would then be able to ask more in-depth questions on the following lecture. These exercises would be submitted during the next lecture and would count for marks.

\section{Group discussions}

In the next lecture, the lecturer would randomly select one student's solution and discuss the correctness/validity, accuracy, elegance, and efficiency of that solution with the class. Mistakes would be pointed out and the lecturer would also draw the students' attention to common pitfalls that should be avoided in relation to that particular concept. Ultimately, that solution would be updated, corrected, and enhanced based on the class' inputs and the lecturer's comments. These discussions allowed for interactive and collaborative problem solving and inquiry-based learning. 
All exercise submissions were collected at the end of the lecture and marked by tutors. Each student received extensive formative feedback for them to be better prepared for the project, test and exam.

\section{Weekly workshop}

After having engaged with the exercises and discussions, the students were ready to fully detach and engage with more complex exercises during the weekly workshops. It was during this phase that the Case Study became the fundamental tool which cemented students' understanding and their ability to engage with real life experiences.

When designing the Poppel case study the industry partner ensured that it reflected real life experiences of current industry practices. This created opportunities for students to transform their conceptual knowledge into contextual knowledge. The industry partner also assisted in the development of the workshop exercises and solutions to expose students to realistic messy and illdefined business problems, in line with what they would have experienced in the workplace. The Poppel case study was formulated in such a way that students became aware of the role context played while they conceptualized solutions to the business problems being posed. The workshop exercises were aligned with the concepts and exercises discussed in class.

At the beginning of the INF2009F course, the industry partner introduced and presented the case to the students, with the industry partner taking the role of the "customer" to which students were expected to turn to for clarifications on the business problems and business rules. The case description was intentionally "fuzzy" in some areas to trigger students' enquiry and encourage reflection.

In order to tackle the problems specified in the case description, students were required to participate in weekly 2 hour workshops. During the workshops, they worked in teams of four while engaging in problem solving and modelling tasks required for the completion of the project. Teamwork further allowed for personal growth.

Students were required to apply their skills and knowledge acquired in class to solve the complex business problems specified in the case study. They would discuss ideas and concepts in their respective teams with less scaffolding from the lecturer and the tutors. Lecturers and tutors were present during the workshops but students were encouraged to work more independently and ask for guidance only when necessary. All workshop exercises were be marked by the tutors and students were again given extensive formative feedback.

\section{Stage 3: Fluency}

Phase 3 (P3) interventions required students to become fluent and act autonomously (to some extent). This was first achieved through the completion of the project. In order to complete the project, students were expected to enhance their workshop exercise solutions in light of the formative feedback provided by the tutors. They compiled a Business Case and a User Requirements Specification Document for the INF2009F course as well as a Systems Specification Document and a software solution for the INF2011S course. In both courses, the work project would be completed with limited scaffolding in order to encourage the students to think independently and to give students a real life experience and a feel for practice. Ultimately, in a summative assessment opportunity, the mid-semester test and exam also required the students to apply their knowledge. 


\section{Results and Outcomes}

Throughout the year it was evident that students became more and more committed as they gained experience and understanding of the Poppel case. Since the case described local scenarios, the students could relate to the case study. They attended most lectures and enjoyed doing the project. Towards the end of the year several students requested to do internships at companies with reported success stories, for example, developing and implementing applications that the companies could use immediately.

In a comparison between the final summative assessments of 2013 and 2014, the marks for 2014 were consistently higher in both courses. Student performed better and less of the final student marks appeared in the lower categories. Table 1 provides the categories used at UCT to grade students, whereas Figure 4 and Figure 5 show the percentages of students obtaining grades in a specific categories for both courses.

Table 1: Categories of students' grades

\begin{tabular}{|l|l|}
\hline Grade Category & Grade Range \\
\hline First & $>=75 \%$ \\
\hline Second & $>=70 \%$ and $<75 \%$ \\
\hline Lower Second & $>=60 \%$ and $<70 \%$ \\
\hline Third & $>=50 \%$ and $<60 \%$ \\
\hline Supplementary (Supp) & $>=45 \%$ and $<50 \%$ \\
\hline Fail & $<45 \%$ \\
\hline Duly Performed Refused (DPR) & Not permitted to complete final exam \\
\hline Incomplete (INC) & Deregistered from the course \\
\hline
\end{tabular}

\section{3-2014 Performance Comparison (INF2009F)}

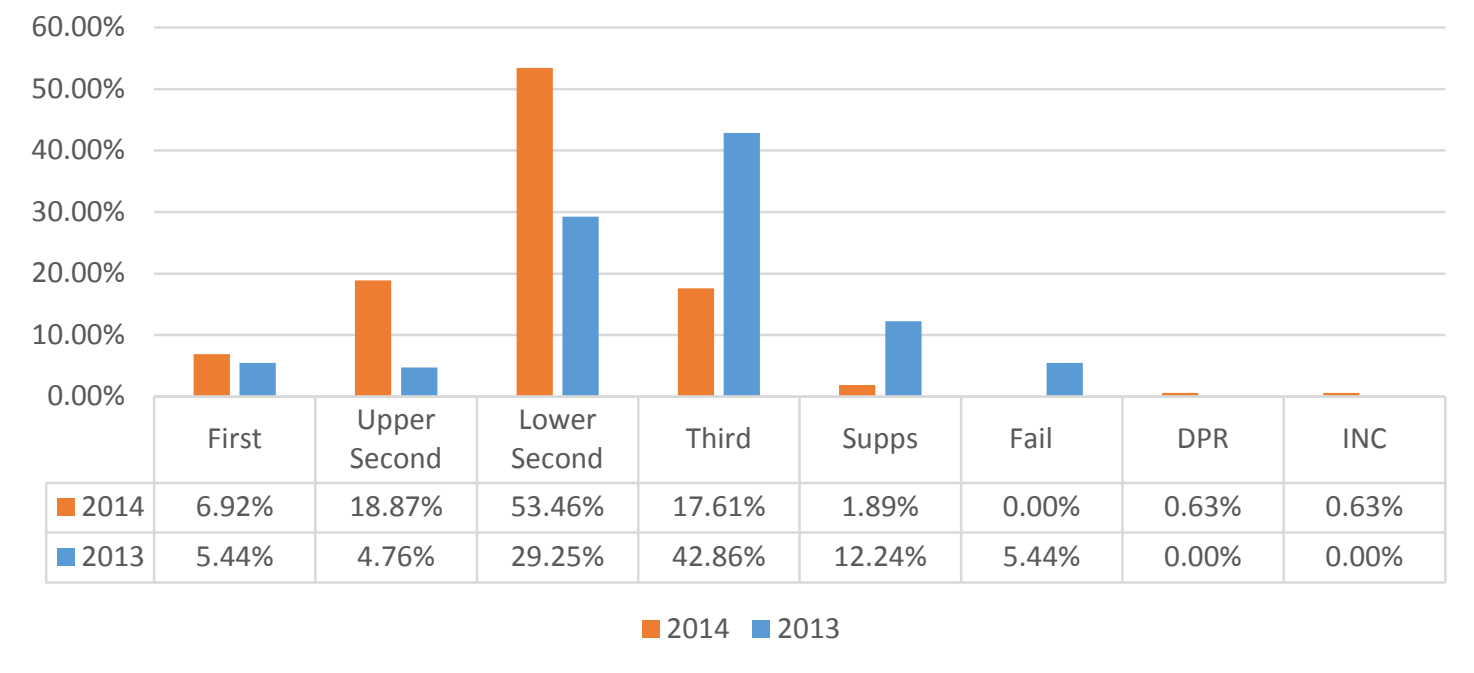

Figure 4: 2013-2014 performance comparison (INF 2009F final grades) 


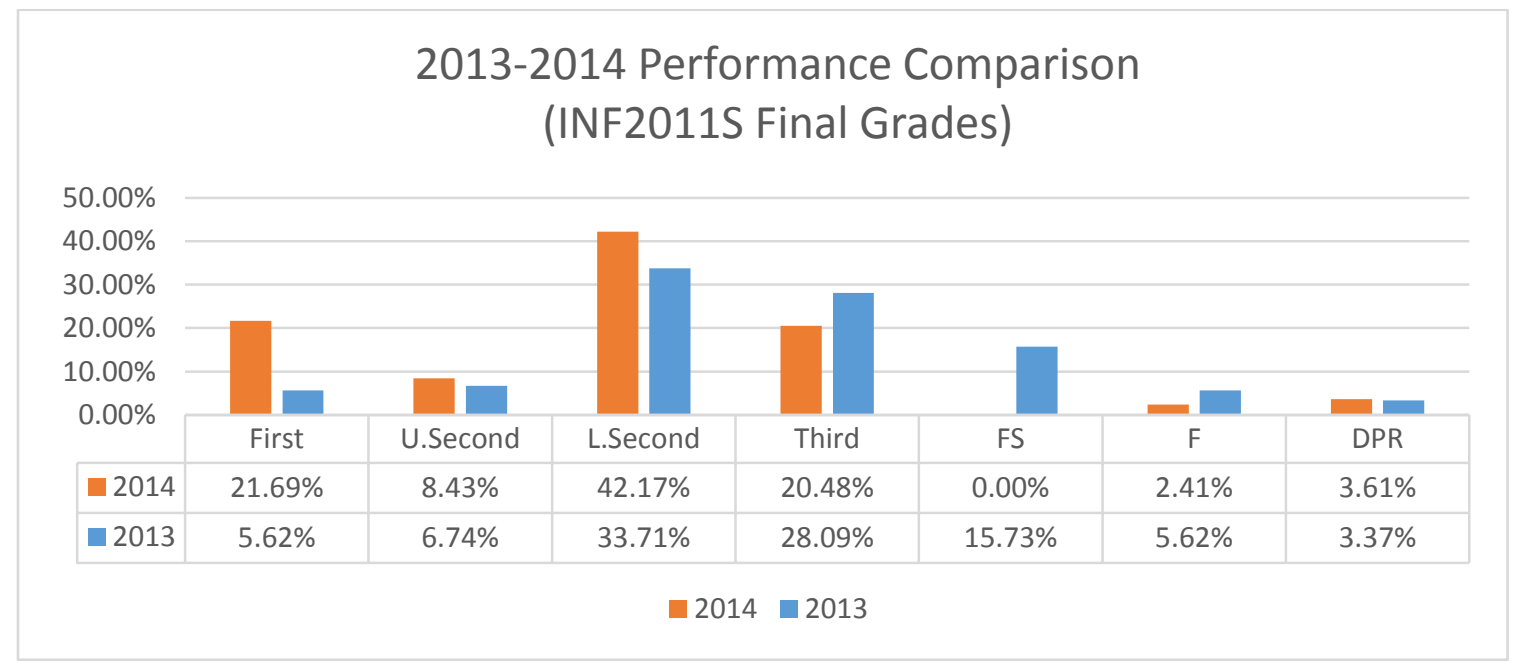

Figure 5: 2013-2014 performance comparison (INF2011S final grades)

Many students agreed that the project they had to develop, was one of their most positive experiences of the year and "the most valuable part of the course". When doing a project students are challenged to be creative and to work more independently, evolving from a novice and an advance beginner to a proficient performer and gaining confidence in doing so. It was worthwhile doing the project as it gave them a sense of accomplishment and "helped them to understand the code". Students also reported in the course evaluations that they learned from team work. They felt that material was communicated effectively and they started to appreciate the link between theory and practice.

Table 2: Student transcendence and outcomes

\begin{tabular}{|l|l|}
\hline \multicolumn{1}{|c|}{ Outcomes } & \multicolumn{1}{|c|}{ Course evaluations } \\
\hline Learning and higher order learning & $\begin{array}{l}\text { Very useful to apply the concepts; exercises were } \\
\text { "very useful" they allowed us to engage with the ma- } \\
\text { terial while it's still fresh in our minds; we really get } \\
\text { to understand what we're learning through class exer- } \\
\text { cises, they're very useful }\end{array}$ \\
\hline Diverse set of skills & $\begin{array}{l}\text { The class discussions helped expand our knowledge } \\
\text { beyond class material. It was useful to get experience } \\
\text { in actually doing the various diagrams. }\end{array}$ \\
\hline Real-life experience & $\begin{array}{l}\text { Workshops and a lot of practical work that helps un- } \\
\text { derstand the theory behind it; } \\
\text { The project allowed me to understand the coding cov- } \\
\text { ered in the course while accomplishing something. It } \\
\text { was very worthwhile } \\
\text { Real-world examples made in the course }\end{array}$ \\
\hline Behavior and student attributes & $\begin{array}{l}\text { Open lines of Communications; Active on the chat } \\
\text { room and that allows any requests to be dealt with } \\
\text { quickly. Enjoy group work; working in teams }\end{array}$ \\
\hline
\end{tabular}




\section{Conclusion}

This paper reported on a particular instance of how a synthesis of theory and practice in undergraduate courses can be used to create thoughtful practitioners. In an attempt to address the gap between what industry requires from IS graduates and the purely theoretical approaches that are often followed at universities, a joint venture with a partner in industry was established. This collaboration led to the development of the Poppel case study that provided a central theme and context for the various interventions throughout the lifecycles of the two undergraduate courses. Poppel simulated the problematic and ambiguous nature of real life scenarios. The workshops and project based deliverables not only challenged students, but also encouraged them to take responsibility for their own learning and gave them an appreciation for the complexity of real life problems. By strengthening industry liaison already in the second year of the degree, an interactive working relationship was established and provided a solid foundation for the capstone course in the following (third) year. As a result of this collaboration, several students took on internships at companies during the long university break.

Since this paper is only an account of the first year of action experiments for second year courses, further refinement of the implementation of the theory is necessary in subsequent action experiments. It is also envisaged to include the other second year courses in similar ventures. Although it is still too early to make any claims on the effectiveness of bridging the skills gap between academia and industry, this approach certainly added value to these courses. One student reported in the course evaluations that "more than anything, I never did prior work in any of my courses, but now I do, and my marks are much better, and I understand topics discussed in class much better", while another student said that "I have really enjoyed this course thus far as the workshops employ practical skill and emphasize group work and group skills".

\section{References}

Beard, D., Schwieger, D., \& Surendran, K. (2007). Incorporating soft skills into accounting and MIS Curricula. Paper presented at the ACM SIGMIS CPR Conference on Computer Personnel Research: The global information technology workforce (SIGMIS-CPR2007), St Louis, MO, USA.

Biggs, J., \& Tang, C. (2011). Teaching for quality learning at university: What the student does (4th ed.). Maidenhead, Berkshire, UK: Open University Press.

Checkland, P. (1972). Towards a systems-based methodology for real-world problem solving. Journal of Systems Engineering, 3(2), 87-116.

Cicmil, S. (2006). Understanding project management practice through interpretive and critical research perspectives. Project Management Journal, 37(2), 27-37.

Cockburn, A. (2002). Agile software development: Pearson Education, Inc.

Dreyfus, H., \& Dreyfus, S. (1986). Mind over machine: The power of human intuition and expertise in the era of the computer. New York, NY, USA: Free Press.

Entwistle, N. (2000). Promoting deep learning through teaching and assessment: Conceptual frameworks and educational contexts. Paper presented at the Teaching and Learning Research Programme Conference, Leicester, UK.

Entwistle, N. J., \& Peterson, E. R. (2004). Conceptions of learning and knowledge in higher education: Relationships with study behaviour and influences of learning environments. International Journal of Educational Research, 41(6), 407-428.

Flyvbjerg, B. (2006). Five misunderstandings about case-study research. Qualitative Inquiry, 12(5), 219245. 
Gallivan, M. J., TruexIII, D. P., \& Kvasny, L. (2004). Changing patterns in IT skill sets 1988-2003: A content analysis of classified advertising. The DATA BASE for Advances in Information Systems, 35(3), 64-85.

Gerogiannis, V. C., \& Fitsilis, P. (2006). Project-based learning as a teaching method for ERP systems. Paper presented at the 3rd International Conference on Enterprise Systems and Accounting (ICESAcc'06), Santorini Island, Greece.

Gorgone, J. T., Davis, G. B., Valacich, J. S., Topi, H., Feinstein, D. L., \& Longenecker(jr), H. E. (2002, 10 November). IS 2002 model curriculum and guidelines for undergraduate degree programs in information systems Retrieved 3 December, 2003, from http://www.acm.org/education/is2002.pdf

Gregor, S., \& Jones, D. (2007). The anatomy of a design theory. Journal of the Association for Information Systems (JAIS), 8(5), 312-335.

Gupta, J. N. D., \& Wachter, R. M. (1998). A capstone course in the information systems curriculum. International Journal of Information Management, 18(6), 427-441.

Hirschheim, R., \& Klein, H. K. (2012). A glorious and not-so-short history of the information systems field. Journal of the Association for Information Systems (JAIS), 13(4), 188-235.

Jenkins, T. (2002). On the difficulty of learning to program. Paper presented at the 3rd Annual Conference of the LTSN Centre for Information and Computer Sciences (LTSN-ICS2002), Loughborough University, Loughborough, UK.

Kolb, D. A. (1984). Experiential learning: Experience as the source of learning and development. Englewood Cliffs, NJ: Prentice Hall.

Kroeze, J. H., Lotriet, H. H., Mavetera, N., Pfaff, M. S., Postma, D. J. v. R., Sewchurran, K., \& Topi, H. (2011). ECIS 2010 panel report: Humanities-enriched information systems. Communications of the Association for Information Systems (CAIS), 28(1), 373-392.

Kuechler, B., \& Vaishnavi, V. (2008). On theory development in design science research: Anatomy of a research project. European Journal of Information Systems (EJIS), 17(5), 489-504.

Land, F., Loebbecke, C., Angehrn, A. A., Clemons, E. K., Hevner, A. R., \& Mueller, G. (2009). ICIS 2008 panel report: Design science in information systems: Hegemony, bandwagon, or new wave? Communications of the Association for Information Systems (CAIS), 24(1), 501-108.

Marsick, V. J., \& O'Niel, J. (1999). The many faces of action learning. Management Learning, 30 (2), 159176.

Maturana, H. R., \& Varela, F. J. (1987). The tree of knowledge: The biological roots of human understanding (R. Paolucci, Trans.). Boston, MA, USA: Shambhala Publications, Inc.

McMurtrey, M. E., Downey, J. P., Zeltmann, S. M., \& Friedman, W. H. (2008). Critical skill sets of entrylevel IT professionals: An empirical examination of perceptions from field personnel. Journal of Information Technology Education (JITE), 7, 101-120. Retrieved from http://www.jite.org/documents/Vol7/JITEv7p101-120McMurtrey312.pdf

Mendoza, R. A., \& Ellis, H. J. C. (2003). Knowledge transfer in IS education: A project-based pedagogical approach to bridging the applicability gap. Journal of Computing Sciences in Colleges, 18(3), 87-99.

Merleau-Ponty, M. (1962). Phenomenology of perception. London, UK: Routledge and Kegan Paul.

Moore, R. C. (Ed.). (2006). Direct measures: The capstone course. Erlbaum, NJ: Hillsdale.

O'Neill, G., \& McMahon, T. (2005). Student-centred learning: What does it mean for students and lecturers? In G. O’Neill, S. Moore, \& B. McMullin (Eds.), Emerging issues in the practice of university learning and teaching (Vol. 1). Dublin, Ireland: AISHE.

Raelin, J. A. (2007). Toward an epistemology of practice. Academy of Management Learning \& Education, 6(4), 495-519.

Ramsden, P. (2003). Learning to teach in higher education (2nd ed.). London, UK: RoutledgeFalmer. 
Richards, D., Marrone, M., \& Vatanasakdakul, S. (2011). What does an information systems graduate need to know? A focus on business analysts and their role in sustainability. Paper presented at the 22nd Australasian Conference on Information Systems (ACIS2011), Sydney, Australia.

Rogerson, C., \& Scott, E. (2010). The fear factor: How it affects students learning to program in a tertiary environment. Journal of Information Education Technology (JITE), 9, 147-171. Retrieved from http://www.jite.org/documents/Vol9/JITEv9p147-171Rogerson803.pdf

Scott, E. (2012). Towards coherent practice in capstone courses for IS majors. PhD, University of Cape Town, Cape Town.

Seymour, L., Scott, E., Meyerowitz, J., Malamoglou, S., \& Morar, A. (2006). Skills learnt during a systems development course: Graduate perceptions of skills transfer and industry alignment. Information Systems Education Journal (ISEDJ), 4(23), 1-13.

Tedre, M., Sutinen, E., Käkhönen, E., \& Kommers, P. (2003). Appreciating the knowledge of students in computer science education in developing countries. Paper presented at the International Conference on Information Technology: Research and Education (ITRE 2003), Newark, New Jersey, USA.

Topi, H., Valacich, J. S., Wright, R. T., Kaiser, K., Jay F. Nunamaker, J., Janice C, S., \& deVreede, G. J. (2010). IS 2010: Curriculum guidelines for undergraduate degree programs in information systems. Communications of the Association for Information Systems (CAIS), 26(1), 359-428.

Webb, G. (1997). Deconstructing deep and surface: Towards a critique of phenomenography. Higher Education, 33, 195-212.

Zuber-Skerritt, O. (2002). The concept of action learning. The Learning Organization, 9(3), 114-124.

\section{Biographies}

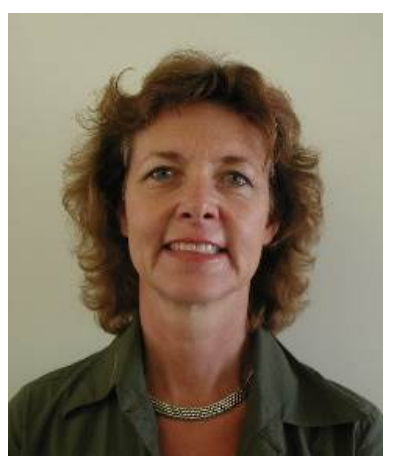

Dr Elsje Scott is an associate professor at the Department of Information Systems, University of Cape Town and has 25 years' experience in teaching programming and systems development project related courses at tertiary institutions. The author's main research interest is the practice of capstone courses, comprising the integrated and interactive environments of project management, systems development, technology and people. This research-led pedagogy resulted in the development of a theory of coherent practice for capstone courses as published the author's PhD study, in 2012.

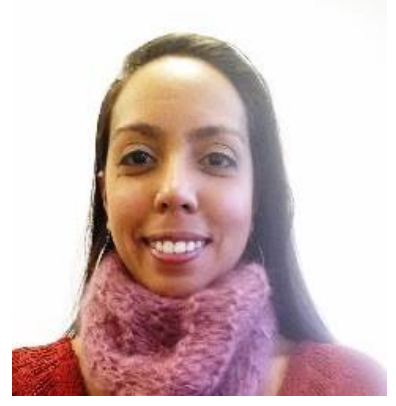

Dr Maureen Tanner has been teaching systems analysis and design at the Department of Information Systems of the University of Cape Town since 2009. Her research interests lie in Agile software development related issues (for both collocated and distributed teams), UML, software engineering and social aspects of social engineering, global software development, virtual teams, and team collaboration. 